\title{
Beneficial effects of the novel cholecystokinin agonist (pGlu-GIn)-CCK-8 in mouse models of obesity/diabetes
}

\author{
N. Irwin • P. Frizelle $\cdot$ I. A. Montgomery • \\ R. C. Moffett • F. P. M. O'Harte • P. R. Flatt
}

Received: 15 May 2012 / Accepted: 18 June 2012 / Published online: 20 July 2012

(C) Springer-Verlag 2012

\begin{abstract}
Aims/hypothesis Cholecystokinin (CCK) is a rapidly degraded gastrointestinal peptide that stimulates satiety and insulin secretion. We aimed to investigate the beneficial weight-lowering and metabolic effects of the novel N-terminally modified CCK analogue, (pGlu-Gln)-CCK-8. Methods The biological actions of (pGlu-Gln)-CCK-8 were comprehensively evaluated in pancreatic clonal BRIN BD11 cells and in vivo in high-fat-fed and $o b / o b$ mice.

Results (pGlu-Gln)-CCK-8 was completely resistant to enzymatic degradation and its satiating effects were significantly $(p<0.05$ to $p<0.001)$ more potent than CCK-8. In BRIN-BD11 cells, (pGlu-Gln)-CCK- 8 exhibited enhanced $(p<0.01$ to $p<0.001)$ insulinotropic actions compared with CCK-8. When administered acutely to high-fat-fed or $o b / o b$ mice, (pGlu-Gln)-CCK-8 improved glucose homeostasis. Sub-chronic twice daily injections of (pGlu-Gln)-CCK-8 in high-fat-fed mice for 28 days significantly decreased body weight ( $p<0.05$ to $p<0.001$ ), accumulated food intake ( $p<$ 0.05 to $p<0.001)$, non-fasting glucose $(p<0.05)$ and triacylglycerol deposition in pancreatic $(p<0.01)$, adipose $(p<$ $0.05)$ and liver $(p<0.001)$ tissue, and improved oral $(p<$ $0.05)$ and i.p. $(p<0.05)$ glucose tolerance and insulin sensitivity $(p<0.001)$. Similar observations were noted in $o b / o b$ mice given twice daily injections of (pGlu-Gln)-CCK-8. In addition, these beneficial effects were not reproduced by simple dietary restriction and were not associated with
\end{abstract}

Electronic supplementary material The online version of this article (doi:10.1007/s00125-012-2654-6) contains peer-reviewed but unedited supplementary material, which is available to authorised users.

N. Irwin $(\varangle) \cdot$ P. Frizelle $\cdot$ I. A. Montgomery $\cdot$ R. C. Moffett F. P. M. O'Harte $\cdot$ P. R. Flatt

SAAD Centre for Pharmacy and Diabetes, School of Biomedical

Sciences, University of Ulster,

Coleraine, Northern Ireland, BT52 1SA, UK

e-mail: n.irwin@ulster.ac.uk changes in energy expenditure. There was no evidence for development of tolerance to (pGlu-Gln)-CCK-8, and analysis of histology or blood-borne markers for pancreatic, liver and renal function in mice treated with (pGlu-Gln)-CCK8 suggested little abnormal pathology.

Conclusions/interpretation These studies emphasise the potential of (pGlu-Gln)-CCK-8 for the alleviation of obesity and insulin resistance.

Keywords Cholecystokinin (CCK) · Diabetes · Drug tolerance - Glucose tolerance $\cdot$ High fat $\cdot$ Insulin sensitivity . Obesity
Abbreviations
CCK
GIP
GLP-1
Cholecystokinin
MALDI-TOF Matrix-assisted laser desorption ionisation time-of-flight

\section{Introduction}

It is generally now accepted that the major physiological role of the gut-derived peptide cholecystokinin (CCK) is in the short-term regulation of energy balance through stimulation of satiety $[1,2]$. CCK exists in multiple molecular forms ranging from 58 to $39,33,22,8$ and 4 amino acids in length [3], but the carboxy-terminal octapeptide, CCK- 8 , is well conserved among species and is the smallest form that retains the full range of biological actions [4]. The biological actions of $\mathrm{CCK}$ are mediated through two receptors, $\mathrm{CCK}_{1}$ and $\mathrm{CCK}_{2}$, which are predominantly located in the periphery and central nervous system, respectively [5]. Intestinally released CCK-8 cannot cross the blood-brain barrier and the potent short-term effect of CCK-8 on inhibiting food intake 
is believed to be mediated peripherally via the vagus nerve [2].

CCK is now known to play a significant role in a number of other important physiological processes including insulin secretion, gastric emptying, bowel motility and pancreatic enzyme secretion [6]. Recent evidence suggests that CCK also acts as a pancreatic beta cell growth factor and antiapoptotic agent [7]. This action profile is reminiscent of that displayed by the incretin hormones glucagon-like peptide 1 (GLP-1) and glucose-dependent insulinotropic polypeptide (GIP) [8]. Much recent attention has been devoted to enhancement of incretin action in the clinical setting using dipeptidyl peptidase 4 inhibitors or stable analogues of GLP-1 for the treatment of type 2 diabetes [9]. Thus, CCK possesses a number of biological actions that would suggest potential therapeutic application for obesity/diabetes. The focus on gut-hormone-based therapies over the past decade has concentrated on the classical incretins, which are secreted in response to glucose ingestion [9]. In reality, meals consist of a mixture of components and nutrients that release a number of other gut-derived hormones, including CCK, that may have potential therapeutic implications [10].

Rapid plasma degradation of CCK poses a major obstacle in the realisation of its clinical use. Other possible barriers to the use of CCK-based peptides in the clinic include development of tolerance [11], induction of taste aversion [12] and induction of pancreatic inflammation [13]. Plasmamediated degradation of CCK is poorly understood and a number of enzymes have been postulated to be involved [14]. Thus, the use of enzyme inhibitors to prolong the biological action of CCK is fraught with difficulties [15]. A more specific approach would therefore be to generate enzymatic-resistant analogues of CCK to extend the biological half-life of the peptide. Studies have already indicated that N-terminal modification or PEGylation of peptide hormones, including CCK, prevents enzymatic degradation and extends biological action $[11,16]$.

In the present study, we generated (pGlu-Gln)-CCK-8, an $\mathrm{N}$-terminally modified CCK-8 peptide analogue. We demonstrated the metabolic stability and in vitro biological activity of (pGlu-Gln)-CCK-8 compared with native CCK-8. Furthermore, the in vivo therapeutic potential of this analogue was assessed using high-fat-fed and obese diabetic $(o b / o b)$ mice. The results provide the experimental evidence that enzyme-resistant (pGlu-Gln)-CCK-8 may provide an effective means of treating obesity/diabetes.

\section{Methods}

Peptide synthesis All peptides were obtained from the American peptide company (Sunnyvale, CA, USA). The specific $\mathrm{CCK}_{1}$ and $\mathrm{CCK}_{2}$ receptor antagonists, SR27897 and LY288513, were purchased from Tocris Biosciences (Avonmouth, UK). Peptides were characterised using matrix-assisted laser desorption ionisation time-of-flight (MALDI-TOF) mass spectrometry [17].

Cell culture and measurement of insulin release Clonal pancreatic BRIN-BD11 cells were used. The origin, characteristics and culture conditions of this cell line are detailed elsewhere [18]. Insulin secretion studies were conducted as described previously [17] and insulin concentrations measured by radioimmunoassay [19].

Acute in vivo effects Experimental mice (Harlan, Oxon, UK) had free access to drinking water and standard rodent maintenance $(10 \%$ fat, $30 \%$ protein and $60 \%$ carbohydrate; Trouw Nutrition, Northwich, UK) or high-fat (45\% fat, $35 \%$ carbohydrate and 20\% protein; Special Diet Services, Witham, UK) diet as appropriate. Before commencement of studies, high-fat-fed mice were maintained on high-fat diet from 6 weeks of age for 140 days. Obesity, insulin resistance and hyperglycaemia were clearly manifested as judged by body weight, plasma insulin and glucose analyses. All animal experiments were carried out in accordance with the UK Animals (Scientific Procedures) Act 1986. The mice were housed individually in an air-conditioned room at $22 \pm$ $2^{\circ} \mathrm{C}$ with a 12 -h light-dark cycle.

In the first series of experiments, 18-h-fasted normal (12to 15-week-old) and high-fat-fed mice received an i.p. injection of glucose alone $(18 \mathrm{mmol} / \mathrm{kg})$ or in combination with CCK-8 or (pGlu-Gln)-CCK-8 (both at $25 \mathrm{nmol} / \mathrm{kg}$ ) and plasma glucose and insulin were assessed. In a separate set of experiments, non-fasted normal (12- to 15-week-old) mice received an i.p. injection of insulin $(20 \mathrm{U} / \mathrm{kg})$ alone or in combination with (pGlu-Gln)-CCK-8 $(25 \mathrm{nmol} / \mathrm{kg}$ ) and plasma glucose was assessed at the times indicated on figures.

In a second series of experiments, normal mice habituated to a daily feeding regime of $3 \mathrm{~h} /$ day were used to assess the dose- and time-dependent effects of CCK-8 peptides on food intake. Mice received an i.p. injection of saline alone $(0.9 \%$ [wt $/ \mathrm{vol}$. $] \mathrm{NaCl})$ or in combination with CCK-8, nonsulphated CCK-8 or (pGlu-Gln)-CCK-8 (5-100 nmol/kg) and food intake was measured at 30-min intervals.

Sub-chronic metabolic effects in high-fat-fed mice Over a 28-day period, male Swiss NIH mice maintained on high-fat $(45 \%)$ diet from 6 weeks of age for 140 days on reversed light cycle (lights off from 09:30 to 21:30 h) received twice daily i.p. injections (09:00 and 17:00 h) of either saline vehicle $(0.9 \%$ [wt/vol.] $\mathrm{NaCl})$ or (pGlu-Gln)-CCK$8(25 \mathrm{nmol} / \mathrm{kg})$. Food intake and body weight were recorded every 3-4 days while non-fasting plasma glucose and insulin concentrations were monitored $(10: 00 \mathrm{~h})$ at intervals of 
3-6 days. On day 28, a non-fasted 12-h glucose profile was conducted during the dark cycle. In addition, i.p. glucose tolerance $(18 \mathrm{mmol} / \mathrm{kg})$ and insulin sensitivity $(20 \mathrm{U} / \mathrm{kg})$ tests were performed on day 28 in non-fasted mice. Mice fasted for $18 \mathrm{~h}$ were used to examine the metabolic response to 15 min feeding. All acute tests commenced at 10:00 h. Pancreatic, liver, gastrocnemius muscle and subcutaneous adipose tissues were excised at the end of the treatment period and stored for histology where appropriate or processed for measurement of triacylglycerol content [20]. Blood triacylglycerol content was also assessed at the end of the study. Details of mice used for clinical chemistry and analytical techniques are given in the electronic supplementary material (ESM) Methods. In addition, the effects of subchronic administration of (pGlu-Gln)-CCK-8 on aspects of indirect calorimetry, behaviour and diet preference were examined in high-fat-fed mice (see ESM Methods for full details). In other studies in high-fat-fed mice, effects of pair feeding to (pGlu-Gln)-CCK-8 for 16 days were assessed.

Sub-chronic metabolic effects in obese diabetic (ob/ob) mice In a second set of sub-chronic experiments, 14- to 18 -week-old obese diabetic $(o b / o b)$ mice, derived from the colony originally maintained at Aston University (Birmingham, UK) [21], received twice daily i.p. injections (09:00 and 17:00 h; lights off 09:30-21:30 h) of either saline vehicle $(0.9 \%$ [wt/vol.] $\mathrm{NaCl})$ or (pGlu-Gln)-CCK-8 $(25 \mathrm{nmol} / \mathrm{kg}$ ) for 18 days. Body weight, food intake, nonfasting plasma glucose and insulin concentrations were recorded as described above. In addition, i.p. glucose tolerance $(18 \mathrm{mmol} / \mathrm{kg})$ and insulin sensitivity $(50 \mathrm{U} / \mathrm{kg})$ tests were performed at the end of the study in non-fasted mice. In a separate set of experiments, after 18 days of treatment with (pGlu-Gln)-CCK-8, mice were divided into two groups and fasted for $18 \mathrm{~h}$. On day 19, one group received an i.p. injection of saline alone $(0.9 \%$ [wt $/ \mathrm{vol}.] \mathrm{NaCl})$ and the other received (pGlu-Gln)-CCK-8 (25 nmol/kg). Food was presented to mice immediately following injection and the amount eaten was recorded every $30 \mathrm{~min}$ up to and including $300 \mathrm{~min}$. Mice received no further treatments and the test was repeated on days 21 and 25 .

Biochemical analysis All blood samples were taken from the cut tip of the tail vein of conscious mice at the times indicated in the figures and immediately centrifuged using a Beckman microcentrifuge (Beckman Instruments, Galway, $\mathrm{UK}$ ) for $30 \mathrm{~s}$ at $13,000 \times \mathrm{g}$. The resulting plasma was then portioned into fresh Eppendorf tubes and stored at $-20^{\circ} \mathrm{C}$ before glucose, insulin and triacylglycerol determinations. Glucose was assayed by an automated glucose oxidase procedure using a Beckman Glucose Analyzer II (Beckman Instruments). Insulin was determined by a modified dextrancoated charcoal radioimmunoassay [19]. Glucagon was measured by an electrochemiluminescent immunoassay using a SECTOR Imager 2400 (Meso Scale Discovery, Gaithersburg, MD, USA). Plasma and tissue triacylglycerol levels were measured as described previously [20].

Statistical analysis Results are expressed as mean \pm SEM. Data were compared using ANOVA, followed by a StudentNewman-Keuls post hoc test. AUC analyses were calculated using the trapezoidal rule with baseline subtraction. A $p$ value $<0.05$ was considered to be statistically significant.

\section{Results}

In vitro degradation CCK-8 was completely and sequentially degraded from the $\mathrm{N}$-terminus by single amino acid deletions (ESM Fig. 1a-c). In contrast, (pGlu-Gln)-CCK8 remained fully intact up to and including the $240 \mathrm{~min}$ incubation period (ESM Fig. 1d, e). ESM Fig. 2a depicts the relative abundance of CCK- 8 degradation fragments as they appeared at each of the time points analysed.

Effects on in vitro insulin secretion and food intake in normal mice CCK-8 and (pGlu-Gln)-8 significantly ( $p<$ 0.05 to $p<0.001)$ stimulated insulin release, in a concentration-dependent manner, from BRIN-BD11 cells (Fig. 1a). In addition, (pGlu-Gln)-CCK-8 was significantly $(p<0.01$ to $p<0.001)$ more potent than CCK-8 (Fig. 1a). Initial in vivo experiments confirmed that sulphation of the tyrosine residue of CCK-8 is essential for appetitesuppressive effects (ESM Fig. 2b). Thus, all further experiments used sulphated versions of CCK- 8 and (pGlu-Gln)CCK-8. Native CCK-8 had a significant $(p<0.001)$ effect on reducing food intake in normal mice (Fig. 1b). However, at $30 \mathrm{~min}$ post injection, only doses of $25 \mathrm{nmol} / \mathrm{kg} \mathrm{CCK}-8$ and above were effective in curtailing food intake (Fig. 1b). Mice treated with (pGlu-Gln)-CCK-8 displayed significant $(p<0.001)$ inhibitory effects on feeding at all doses and time points examined (Fig. 1c). Direct comparison of the relative effects of $25 \mathrm{nmol} / \mathrm{kg}$ CCK-8 and (pGlu-Gln)-CCK-8 on inhibition of feeding revealed (pGlu-Gln)-CCK- 8 to be significantly $(p<0.05$ to $p<0.001)$ more effective than CCK8 (Fig. 1d). The satiating effects of (pGlu-Gln)-CCK-8 were confirmed to be dependent on $\mathrm{CCK}_{1}$ receptor activation since the specific $\mathrm{CCK}_{1}$ receptor antagonist, SR27897, almost completely annulled the feeding-suppressive effects of (pGlu-Gln)-CCK-8, whereas the $\mathrm{CCK}_{2}$ receptor antagonist, LY88513, had no effect (ESM Fig. 2c, d).

Acute metabolic activity in normal, high-fat-fed and ob/ob mice Administration of $25 \mathrm{nmol} / \mathrm{kg}$ CCK- 8 to normal mice resulted in significantly $(p<0.05)$ reduced plasma glucose levels at $60 \mathrm{~min}$ post injection compared with control, with 
a

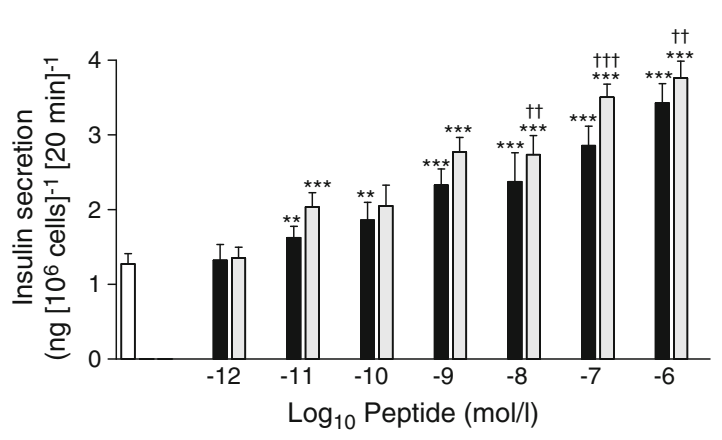

C

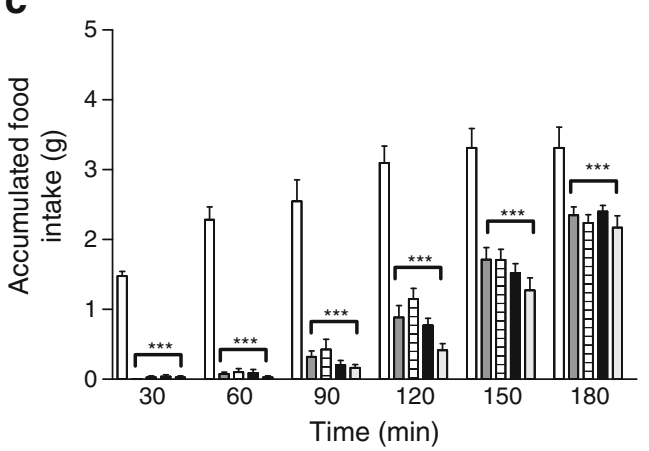

b

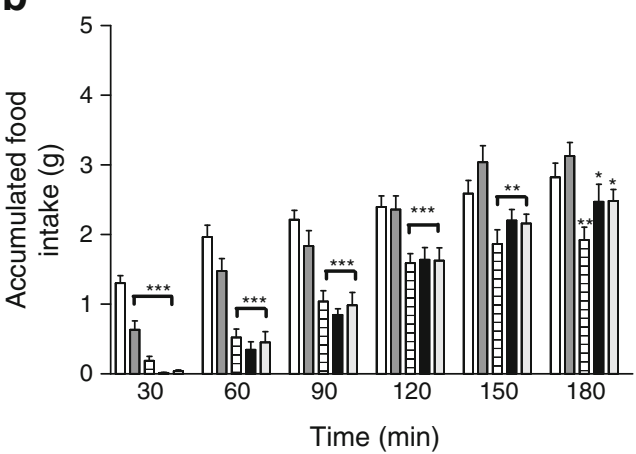

d

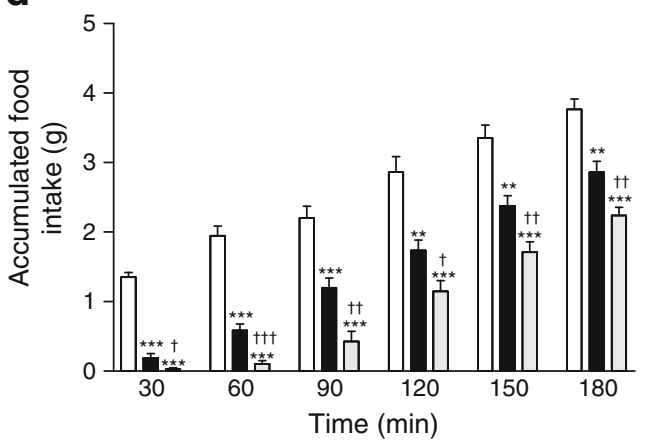

Fig. 1 Effect of CCK-8 and (pGlu-Gln)-CCK-8 on insulin secretion from BRIN-BD11 cells (a) and food intake in normal mice (b-e). (a) Following $40 \mathrm{~min}$ preincubation with a buffer containing $1.1 \mathrm{mmol} / 1$ glucose, the insulinotropic effects of CCK-8 and (pGlu-Gln)-CCK8 were tested in the presence of $5.6 \mathrm{mmol} / \mathrm{l}$ glucose during 20 -min incubations. White bars, $5.6 \mathrm{mmol}$ glucose control; black bars, CCK-8; light-grey bars, (pGlu-Gln)-CCK-8. (b-d) Food intake was monitored in normal mice habituated to a daily feeding regime of $3 \mathrm{~h} /$ day. (b, c) Dose-response effects of i.p. administration of CCK-8 and (pGlu-Gln)CCK-8 (5-100 nmol/ $\mathrm{kg})$. (b) White bars, saline control; dark-grey bars, CCK-8 (5 nmol/kg); striped bars, CCK-8 (25 nmol/kg); black bars, CCK-8 (50 nmol/kg); light-grey bars, CCK-8 (100 nmol/kg). (c) White bars, saline control; dark grey bars, (pGlu-Gln)-CCK-8 ( $5 \mathrm{nmol} / \mathrm{kg}$ ); striped bars, (pGlu-Gln)-CCK-8 (25 nmol/kg); black bars, (pGlu-Gln)-CCK-8 (50 nmol/kg); light-grey bars, (pGlu-Gln)-CCK$8(100 \mathrm{nmol} / \mathrm{kg})$. (d) Comparison of i.p. administration of CCK8 and (pGlu-Gln)-CCK-8 (25 nmol/kg). White bars, saline control; black bars, CCK-8 (25 nmol/kg); light-grey bars, (pGlu-Gln)-CCK$8(25 \mathrm{nmol} / \mathrm{kg})$. Values represent means \pm SEM for eight mice. ${ }^{*} p<$ $0.05, * * p<0.01$ and $* * * p<0.001$ compared with respective control group. ${ }^{\dagger} p<0.05,{ }^{\dagger} p<0.01$ and ${ }^{\dagger \dagger} p<0.001$ compared with CCK-8 no effect on glucose-stimulated insulin (Fig. 2a, b). However, CCK-8 was not associated with significant changes in glucose or insulin in high-fat-fed or $o b / o b$ mice when compared with respective controls (Fig. 2c-f). In addition, (pGlu-Gln)-CCK-8 was without effect on glucose or insulin levels in normal mice when administered in combination with glucose (Fig. 2a, b). However, (pGlu-Gln)-CCK-8 significantly $(p<0.05)$ lowered plasma glucose and increased $(p<0.05)$ glucose-stimulated insulin levels at $60 \mathrm{~min}$ in $o b / o b$ mice (Fig. 2c, d). Furthermore, high-fat-fed mice treated with (pGlu-Gln)-CCK-8 displayed significantly $(p<0.05)$ reduced plasma glucose levels at $30 \mathrm{~min}$ (Fig. 2e), with a similar glucose-induced insulin profile to that of controls (Fig. 2f). Concurrent injection of (pGlu-Gln)-CCK-8 in combination with insulin did not result in any significant effects on glucose concentrations (ESM Fig. 3).

Sub-chronic metabolic effects in high-fat-fed mice Administration of (pGlu-Gln)-CCK-8 twice daily to high-fat-fed mice resulted in significantly $(p<0.05$ to $p<0.001)$ decreased body weight from day 5 onwards accompanied by reduced $(p<0.05$ to $p<0.001)$ accumulated food intake throughout the treatment period (Fig. 3a, b). Non-fasting plasma glucose concentrations were also significantly $(p<$ 0.05 ) lowered in (pGlu-Gln)-CCK-8-treated mice compared with controls on days 17 and 28 (Fig. 3c). No changes in non-fasting plasma insulin were noted (Fig. 3d). Analysis of a 12-h glucose profile on day 28 revealed that (pGlu-Gln)CCK-8 significantly $(p<0.05)$ decreased plasma glucose levels at four of the five observation points (Fig. 3e). Pancreatic histological analysis revealed that both the saline and (pGlu-Gln)-CCK-8 high-fat-treated groups displayed largely conserved islet structure with some signs of oedema and formation of small vacuoles in exocrine tissue (Fig. $3 \mathrm{f}-\mathrm{h}$ ).

Plasma glucose levels in glucose tolerance tests were significantly reduced $(p<0.05)$ at 30 and $60 \mathrm{~min}$ mice treated for 28 days with (pGlu-Gln)-CCK-8 and this was corroborated by a significantly $(p<0.05)$ decreased AUC value 
a
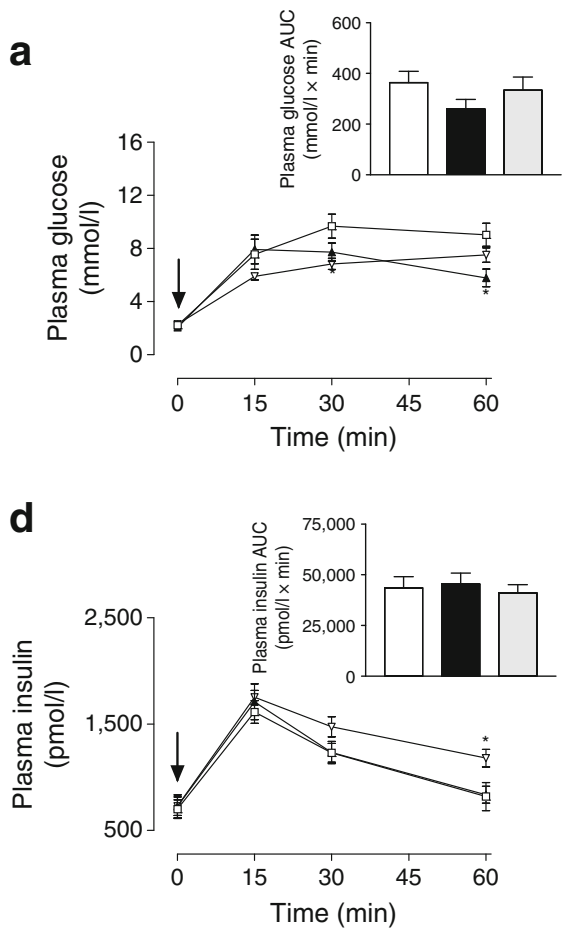

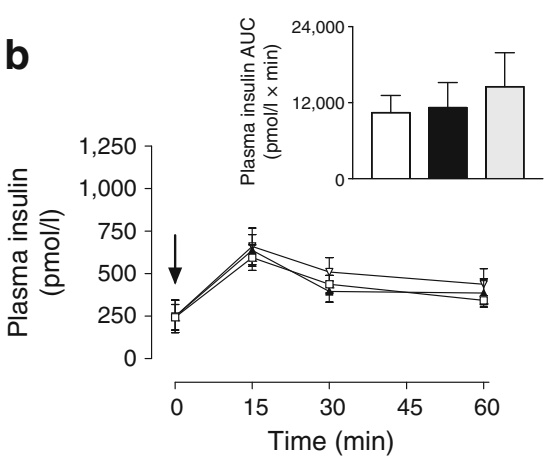

C

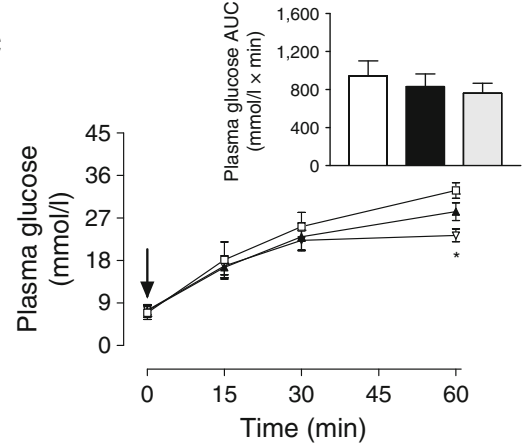

e

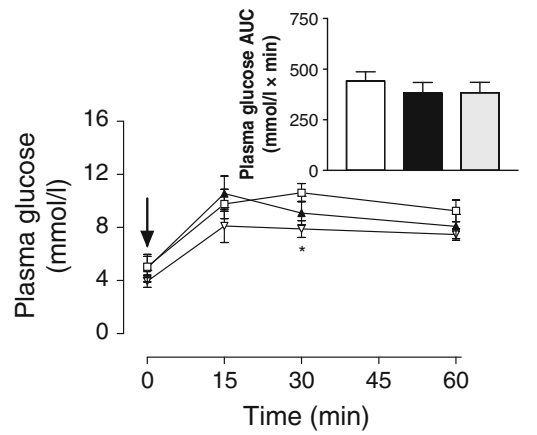

f

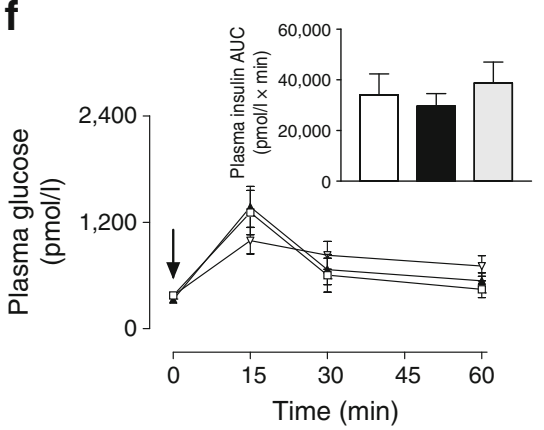

Fig. 2 Glucose-lowering and insulin-releasing effects of CCK-8 and (pGlu-Gln)-CCK-8 in 18-h-fasted normal (a, b) high-fat-fed (c, d) and $o b / o b$ (e, f) mice. Plasma glucose and insulin concentrations were measured before and after i.p. administration of glucose alone $(18 \mathrm{mmol} / \mathrm{kg})$, or in combination with CCK-8 or (pGlu-Gln)-CCK-8 $(25 \mathrm{nmol} / \mathrm{kg})$. The time of injection is indicated by the arrow $(0 \mathrm{~min})$. Squares, glucose

(Fig. 4a). Glucose-stimulated plasma insulin concentrations were not significantly different between groups (Fig. 4b). Plasma glucose responses to 15 min feeding were significantly lowered $(p<0.05)$ at 105 min in (pGlu-Gln)-CCK-8treated mice compared with controls (Fig. 4c). Similarly, the AUC for glucose was significantly $(p<0.05)$ decreased by (pGlu-Gln)-CCK-8 (Fig. 4c), despite the mice having a similar food intake of $0.1-0.3 \mathrm{~g} / \mathrm{mouse} / 15 \mathrm{~min}$. Oralnutrient-stimulated insulin concentrations were not significantly altered between groups (Fig. 4d). The hypoglycaemic action of insulin was significantly $(p<0.001)$ augmented in terms of post-injection and AUC values in mice treated with (pGlu-Gln)-CCK-8 for 28 days (Fig. 4e).

The effects of twice daily (pGlu-Gln)-CCK-8 treatment on preference between standard rodent maintenance and high-fat diet was also assessed in lean-control and highfat-fed mice. Both groups had a greater predilection for the high-fat diet during the 7 days before treatment regimens began (data not shown). Treatment with (pGlu-Gln)-CCK-8 in the ensuing 7 days decreased total accumulated energy intake in both normal $(11.1 \pm 0.9$ vs $6.7 \pm 1.4 \mathrm{~kJ} / \mathrm{g})$ and highfat-fed $(16.5 \pm 1.3$ vs $7.7 \pm 0.8 \mathrm{~kJ} / \mathrm{g})$ mice. However, tendency towards the high-fat diet was still evident as the ratio of standard-to-high-fat diet consumed remained similar throughout the study period in both groups $(16.4 \pm 4.2$ before alone; black triangles, CCK-8; white triangles, (pGlu-Gln)-CCK-8. Plasma glucose and insulin AUC values for 0-60 min post injection are shown in insets. White bars, glucose alone; black bars, CCK-8; light-grey bars, (pGlu-Gln)-CCK-8. Values represent means \pm SEM for eight mice. $* p<0.05$ compared with respective glucose alone

treatment vs $14.5 \pm 3.6$ after treatment and $9.6 \pm 2.5$ before treatment vs $8.6 \pm 2.6$ after treatment in lean control and high-fat-fed mice, respectively). In addition, there were no significant differences in ambulatory activity in high-fat-fed mice treated twice daily for 3 days with (pGlu-Gln)-CCK-8 (ESM Fig. 4a). Likewise, there were no differences in $\mathrm{O}_{2}$ consumption, $\mathrm{CO}_{2}$ production, respiratory exchange ratio and energy expenditure in these mice when food intake but not body weight was suppressed (ESM Fig. 4b-e). Furthermore, similar observations on lack of effect of (pGlu-Gln)CCK-8 on aspects of indirect calorimetry were made following twice daily treatment for 18 days with (pGlu-Gln)-CCK-8 in high-fat-fed mice (data not shown).

Sub-chronic metabolic effects of pair feeding to ( $p G l u$-Gln)$C C K-8$ in high-fat-fed mice (pGlu-Gln)-CCK-8 significantly $(p<0.05$ to $p<0.001)$ decreased accumulated food intake from day 4 onwards (Fig. 5b). Body-weight gain and actual body weights were also significantly $(p<0.05$ to $p<0.001)$ decreased compared with control and pair-fed groups (Fig. 5a). Circulating glucose and insulin were decreased $(p<0.05$ to $p<0.001)$ compared with controls, with lower insulin $(p<0.05$ to $p<0.001)$ in (pGlu-Gln)-CCK-8-treated compared with pair-fed mice (Fig. 5c, d). Non-fasting glucagon levels were similar in all groups (Fig. 5e). 
a

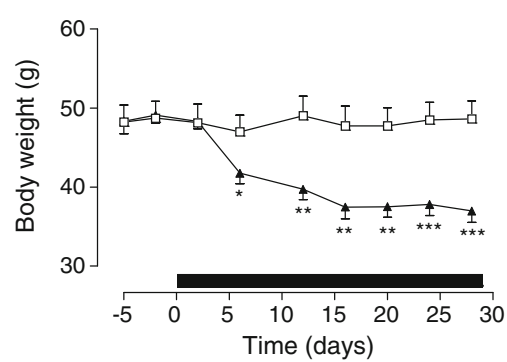

d

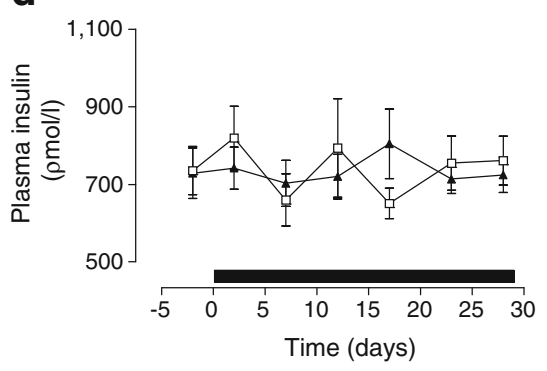

b

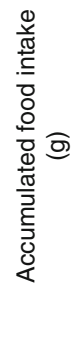

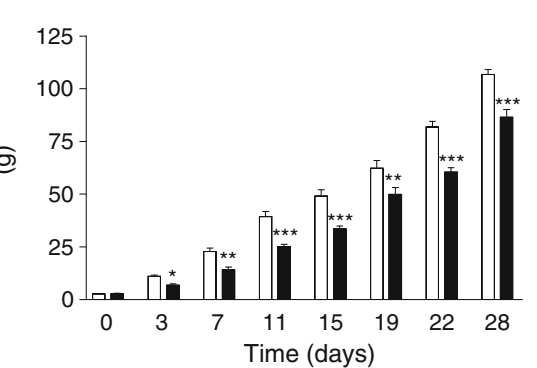

e

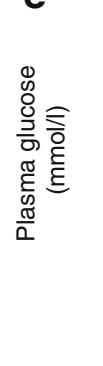

C

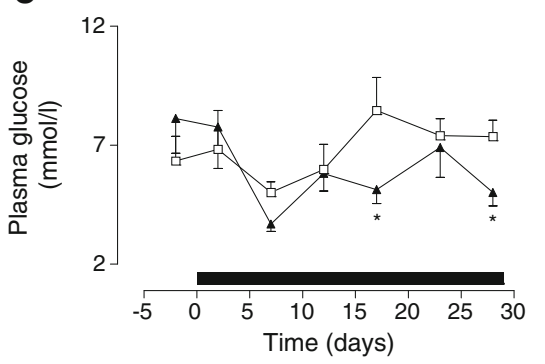

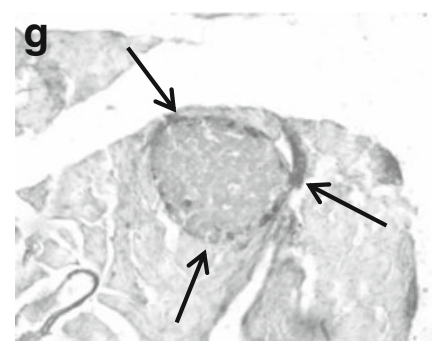

Fig. 3 Effect of twice-daily (pGlu-Gln)-CCK-8 administration on body weight (a), accumulated food intake (b), non-fasting plasma glucose (c) and insulin (d), 12-h glucose profile (e) and pancreatic morphology (f-h) in high-fat-fed mice. (a-d) Variables were measured for 5 days before and 28 days during (indicated by horizontal black bar) treatment with saline or (pGlu-Gln)-CCK-8 (25 nmol/kg). (e) $12-$ $\mathrm{h}$ Glucose profile and $(\mathbf{f}-\mathbf{h})$ pancreatic morphology were assessed after treatment with saline or (pGlu-Gln)-CCK-8 $(25 \mathrm{nmol} / \mathrm{kg})$ for 28 days. Squares, saline; triangles, (pGlu-Gln)-CCK-8. For food intake: white bars, saline; black bars, (pGlu-Gln)-CCK-8. (f-h) Representative images (magnification $\times 40$ ) of pancreases from normal control mice (f) and high-fat-fed mice following 28 days of twice-daily treatment

Individual and overall glucose AUC values were reduced following i.p. $(p<0.05)$ or oral $(p<0.01)$ glucose in (pGluGln)-CCK-8-treated mice compared with controls (Fig. 6a-d). Pair-fed mice exhibited similar overall glycaemic responses to high-fat controls (Fig. 6b, d). The hypoglycaemic action of insulin was significantly $(p<0.05$ to $p<0.01)$ augmented in (pGlu-Gln)-CCK-8-treated, but not pair-fed mice (Fig. 6e, f).

Sub-chronic effects on tissue and plasma triacylglycerol content and clinical chemistry in high-fat-fed mice Triacylglycerol content of pancreatic, adipose and liver tissues were significantly $(p<0.05$ to $p<0.01)$ decreased in (pGluGln)-CCK-8-treated mice compared with high-fat controls with saline (g) or (pGlu-Gln)-CCK-8 $(25 \mathrm{nmol} / \mathrm{kg})$ injection (h). Individual islets are denoted by arrows, showing the central core of beta cells and peripherally located alpha cells. Slides were stained using monoclonal mouse anti-insulin $(1: 1,000)$ and monoclonal antiglucagon $(1: 3,000)$ (both Sigma-Aldrich, Poole, UK) antibodies. The antibodies were visualised using DAB (insulin) and VIP (glucagon, both from Vector Laboratories, Burlingame, CA, USA), respectively, and counterstained with methyl green. Approximately 60-70 random sections were examined from the pancreas of each mouse $(n=6)$. Values are means \pm SEM for eight mice. ${ }^{*} p<0.05, * * p<0.01$ and $* * * p<0.001$ compared with saline group

(ESM Fig. 5a-c). (pGlu-Gln)-CCK-8 had no significant effect on triacylglycerol content of gastrocnemius muscle tissue and plasma compared with high-fat controls (ESM Fig. 5 d, e). Evaluation of biochemical markers of pancreatic inflammation/damage, muscle damage, hepatocellular function and renal function were also examined. Amylase and lipase were unchanged, the only difference $(p<0.05)$ being higher values of alanine aminotransferase/serum glutamic pyruvic transaminase activity in lean controls (ESM Table 1).

Sub-chronic metabolic effects in ob/ob mice Twice-daily administration of (pGlu-Gln)-CCK-8 to $o b / o b$ mice 

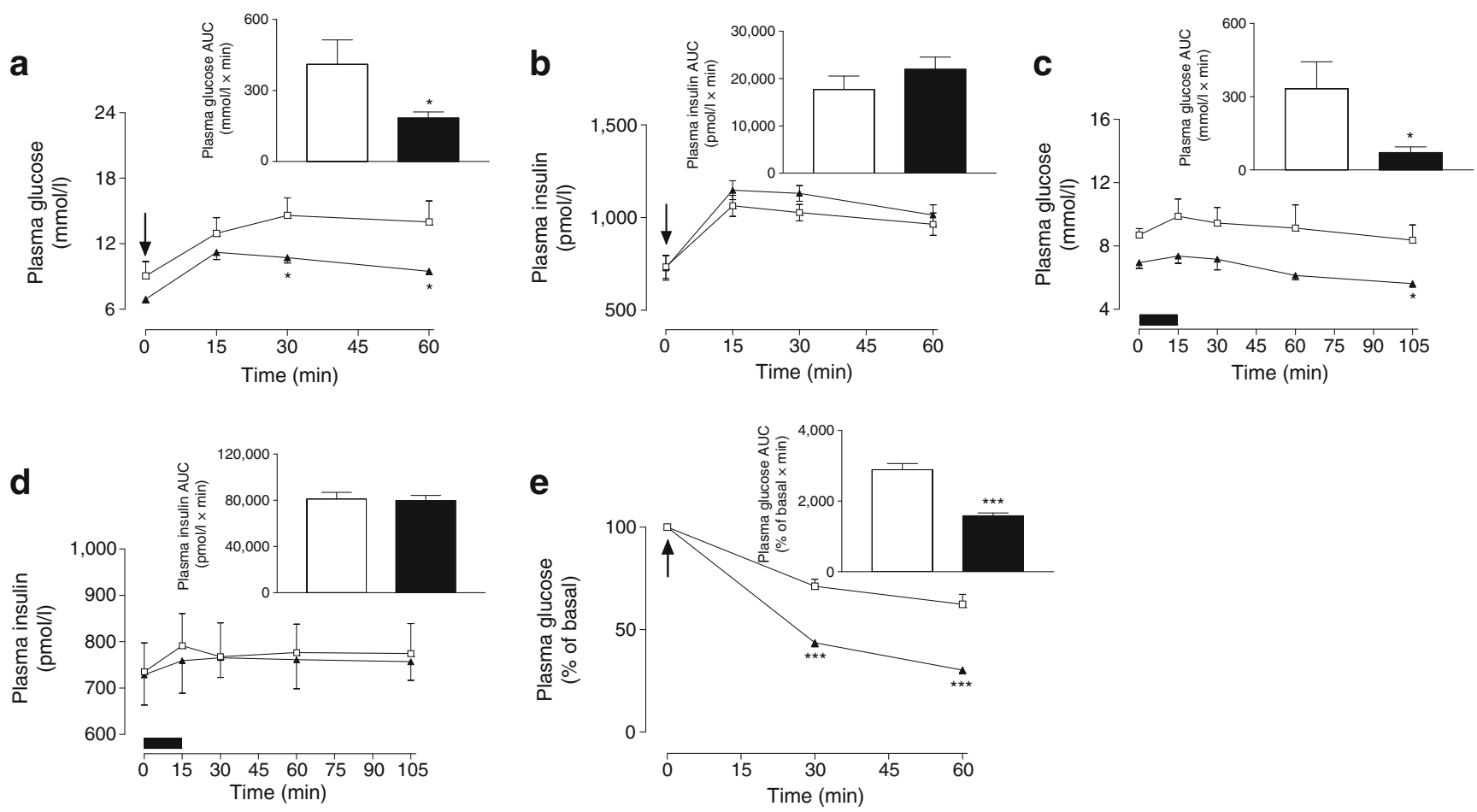

Fig. 4 Effect of twice daily (pGlu-Gln)-CCK-8 administration on glucose tolerance and plasma insulin response to glucose (a, b), glucose and insulin responses to feeding $(\mathbf{c}, \mathbf{d})$ and insulin sensitivity in high-fat-fed mice (e). Tests were conducted after twice daily treatment with saline or (pGlu-Gln)-CCK-8 $(25 \mathrm{nmol} / \mathrm{kg})$ for 28 days. (a, b) Glucose $(18 \mathrm{mmol} / \mathrm{kg})$ was administered to non-fasted mice at the time indicated by the arrow. Plasma glucose and insulin AUC values for 0 60 min post injection are shown in insets. (c, d) Mice were fasted for

$18 \mathrm{~h}$ and allowed to re-feed for 15 min (black horizontal bar indicates time of feeding). Plasma glucose and insulin AUC values for 0 105 min post injection are shown in insets. (e) Insulin $(20 \mathrm{U} / \mathrm{kg}$ ) was administered to non-fasted mice at the time indicated by the arrow. AUC values for 0-60 min post injection are shown in the inset. Squares and white bars, saline; triangles and black bars, (pGlu-Gln)-CCK-8. Values are means \pm SEM for eight mice. ${ }^{*} p<0.05$ and ${ }^{* * *} p<0.001$ compared with saline group

significantly $(p<0.001)$ depressed body weight gain from day 2 onwards (Fig. 7a). Actual body weights on day 18 were $79.9 \pm 8.7$ and $84.2 \pm 6.1 \mathrm{~g}$ for (pGlu-Gln)-CCK-8- and saline-treated $o b / o b$ mice, respectively. This was accompanied by reduced $(p<0.05)$ accumulated food intake on all observation days (Fig. 7b). There was also a strong tendency for lower plasma glucose in (pGlu-Gln)-CCK-8-treated $o b / o b$ mice, but this failed to reach significance (Fig. 7c). Actual blood glucose values on day 18 were $15.8 \pm 3.4$ and $17.6 \pm$ $1.9 \mathrm{mmol} / \mathrm{l}$ for (pGlu-Gln)-CCK-8- and saline-treated mice, respectively. Non-fasting plasma insulin levels were not significantly different between groups (Fig. 7d).

As shown in Fig. 8a, ob/ob mice treated twice daily with (pGlu-Gln)-CCK-8 for 18 days exhibited significantly reduced $(p<0.05$ to $p<0.001)$ plasma glucose concentrations at 0 and $60 \mathrm{~min}$ following an i.p. glucose challenge. This was corroborated by a significantly $(p<0.01)$ decreased 0-60 min AUC value (Fig. 8a). Glucose-stimulated plasma insulin concentrations were not different between groups (Fig. 8b). In addition, (pGlu-Gln)-CCK-8-treated mice had a non-significant tendency towards reduced glucose levels following insulin injection (Fig. 8c, d). The acute effect of (pGlu-Gln)-CCK-8 on inhibiting food intake in $o b / o b$ mice

previously treated with (pGlu-Gln)-CCK-8 twice daily for 18 days was examined following cessation of treatment on days 19, 21 and 25. The inhibiting effect of (pGlu-Gln)CCK-8 administration on appetite was clearly evident as revealed by the significantly $(p<0.05$ to $p<0.001)$ reduced food intake on each of the observation days compared with controls (Fig. 8e-g).

\section{Discussion}

In the present study we have evaluated the stability and actions of a novel analogue of the smallest molecular form of CCK that exhibits a full range of bioactivity, namely (pGlu-Gln)-CCK-8. N-terminally modified (pGlu-Gln)CCK-8 was completely stable to enzymatic breakdown by plasma proteases and exhibited significantly enhanced appetite suppression compared with native CCK-8. (pGluGln)-CCK-8 also stimulated insulin secretion from clonal beta cells and acutely improved glucose homeostasis in $o b / o b$ and high-fat-fed mice. These observations demonstrate the glucose-lowering potential of CCK consistent with a beta cell effect under specific conditions such as high-fat feeding [22]. 
a

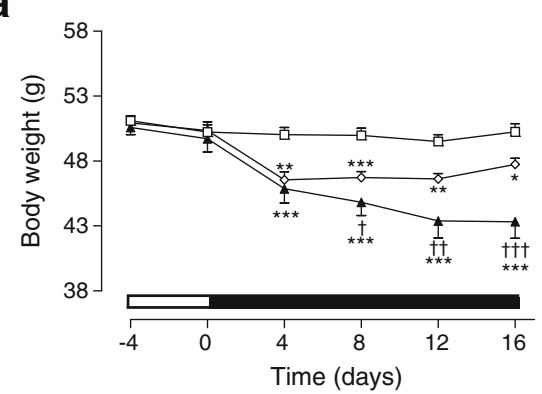

d

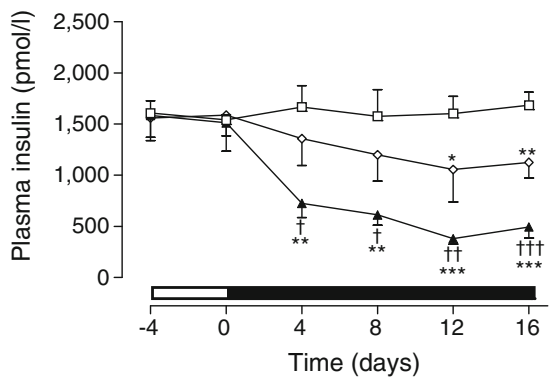

b

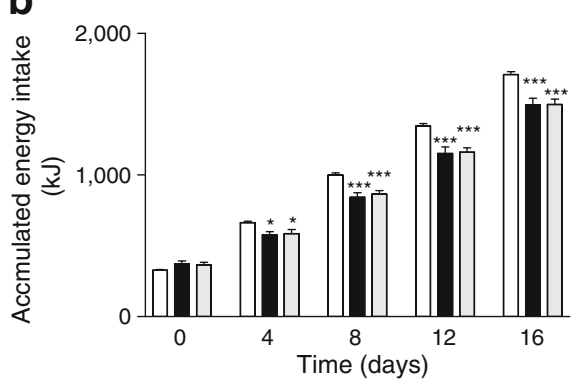

e

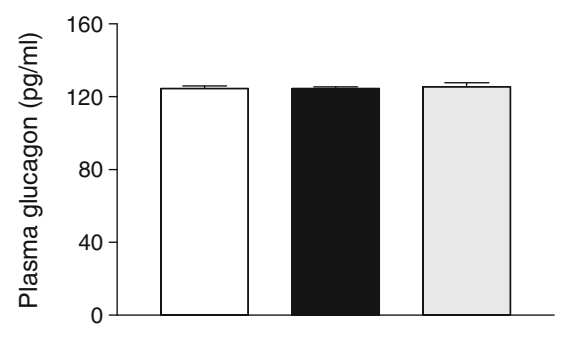

C

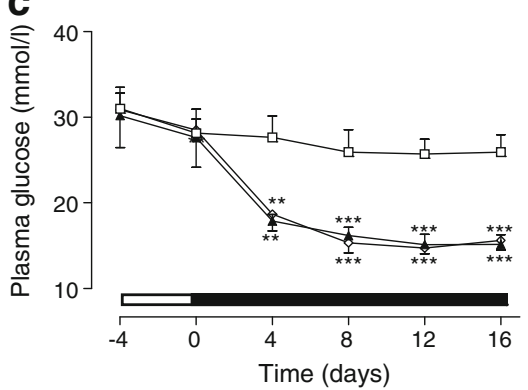

Fig. 5 Effect of twice daily (pGlu-Gln)-CCK-8 administration and pair feeding on body weight (a), accumulated food intake (b), nonfasting plasma glucose (c), and insulin (d) and glucagon (e) in high-fatfed mice. (a-d) Variables were measured for 5 days before and 28 days during (indicated by horizontal black bar) treatment with saline or (pGlu-Gln)-CCK-8 (25 nmol/kg). (e) Glucagon was measured after
28 days treatment with saline or (pGlu-Gln)-CCK-8 (25 nmol/kg). Squares and white bars, saline; triangles and black bars, (pGlu-Gln)CCK-8; diamonds and light-grey bars, pair-fed. Values are means \pm SEM for eight mice. ${ }^{*} p<0.05, * * p<0.01$ and $* * * p<0.001$ compared with saline group. ${ }^{\dagger} p<0.05,{ }^{\dagger \dagger} p<0.01$ and ${ }^{\dagger \dagger \dagger} p<0.001$ compared with pair-fed group a

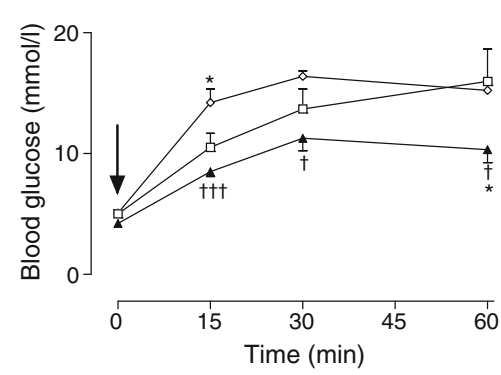

d

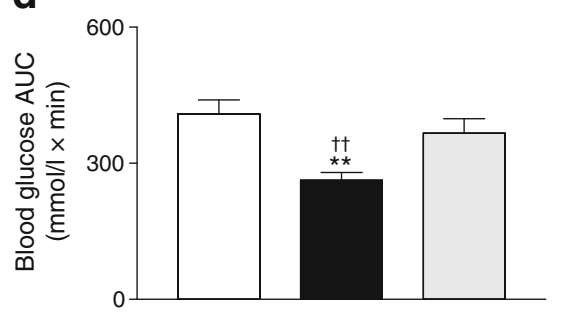

b

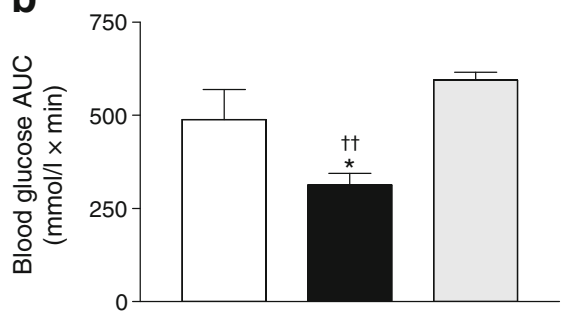

e

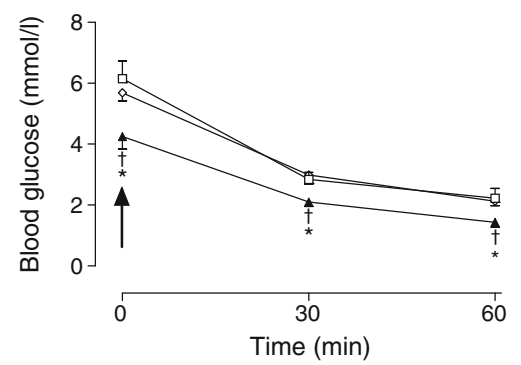

C

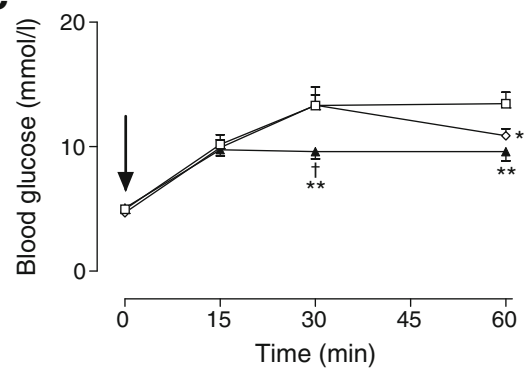

f

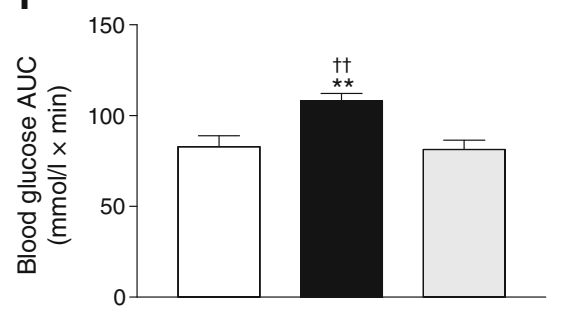

Fig. 6 Effect of twice daily (pGlu-Gln)-CCK-8 administration and pair feeding on intraperitoneal $(\mathbf{a}, \mathbf{b})$ and oral $(\mathbf{c}, \mathbf{d})$ glucose tolerance and insulin sensitivity $(\mathbf{e}, \mathbf{f})$ in high-fat-fed mice. Tests were conducted after twice daily treatment with saline or (pGlu-Gln)-CCK-8 $(25 \mathrm{nmol} / \mathrm{kg}$ ) for 16 days. Mice pair-fed to the (pGlu-Gln)-CCK-8 group were also tested. (a-d) Glucose $(18 \mathrm{mmol} / \mathrm{kg})$ was administered to non-fasted mice intraperitoneally $(\mathbf{a}, \mathbf{b})$ and orally $(\mathbf{c}, \mathbf{d})$ at the time indicated by the arrow. Plasma glucose AUC values for 0-60 min post injection are also shown. (e) Insulin $(20 \mathrm{U} / \mathrm{kg})$ was administered to non-fasted mice at the time indicated by the arrow. (f) AUC values for 0-60 min post injection are also shown. Squares and white bars, saline; triangles and black bars, (pGlu-Gln)-CCK-8; diamonds and light-grey bars, pair-fed. Values are means \pm SEM for eight mice. ${ }^{*} p<0.05$ and $*^{*} p<0.01$ compared with saline group. ${ }^{\dagger} p<0.05,{ }^{\dagger \dagger} p<0.01$ and ${ }^{\dagger \dagger} p<0.001$ compared with pair-fed group 
Fig. 7 Effect of twice-daily (pGlu-Gln)-CCK-8 administration on body weight (a), accumulated food intake (b), nonfasting plasma glucose (c) and insulin concentrations (d) in $o b / o b$ mice. Variables were measured for 4 days before and 18 days during (indicated by horizontal black bar) treatment with saline or (pGlu-Gln)-CCK$8(25 \mathrm{nmol} / \mathrm{kg})$. Squares and white bars, saline; triangles and black bars, (pGlu-Gln)-CCK-8. Values are means \pm SEM for eight mice. ${ }^{*} p<0.05$ and $* * * p<0.001$ compared with saline group
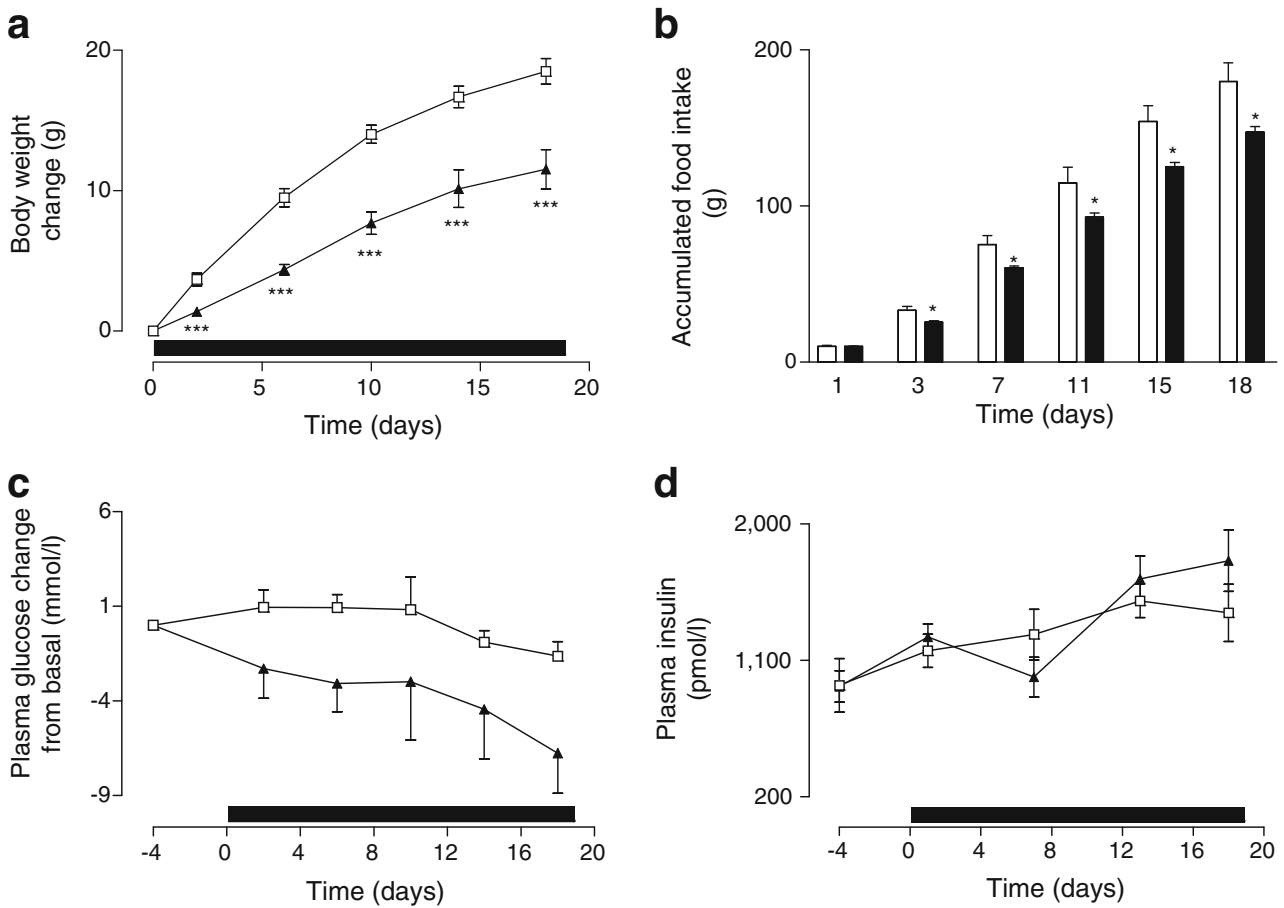

Upregulation of CCK actions is also evident in mice with double genetic knockout of GLP-1 and GIP and in pregnancy, where enhanced beta cell action are key features [23, 24]. Thus, there appears to be a definite functional plasticity of the enteroinsular axis that can be mediated, at least in part, by CCK.

Chronic treatment with (pGlu-Gln)-CCK-8 for 28 days in high-fat-fed mice resulted in a marked improvement in metabolic status. This included decreased food intake and greater than $20 \%$ body-weight loss. The sustained and significant effect of (pGlu-Gln)-CCK-8 on inhibiting feeding would imply that adaptive mechanisms, such as more frequent meals, to normalise energy intake were not an issue in the current setting [6]. In a similar study with the longacting GLP-1 mimetic exenatide (approximately $8 \mathrm{nmol} \mathrm{kg}{ }^{-1}$ day $^{-1}$ ), approximately $16 \%$ body weight was lost over 28 days [25]. We also confirmed, through the use of specific $\mathrm{CCK}_{1}$ and $\mathrm{CCK}_{2}$ receptor antagonists, that the appetite-suppressive effects of (pGlu-Gln)-CCK-8 were mediated peripherally via the $\mathrm{CCK}_{1}$ receptor. The fact that $\mathrm{CCK}_{2}$ receptor inhibition did not perturb the satiating effect of (pGlu-Gln)-CCK-8 is interesting since $\mathrm{CCK}_{2}$ receptor deletion has been associated with increased body weight and hypothalamic neuropeptide Y content [26]. CCK-8 does not cross the blood-brain barrier [2], making accumulation in the brain unlikely even following repeated dosing. Nonetheless, lack of effect of (pGlu-Gln)-CCK-8 on $\mathrm{CCK}_{2}$ receptor action is encouraging given that activation of this receptor has been associated with panic and anxiety attacks $[27,28]$. Indeed, the therapeutic potential of previous CCKbased drugs has been severely limited due to lack of specificity between receptor subtypes [10]. The most recent specific $\mathrm{CCK}_{1}$ receptor agonist, GI181771X, to undergo clinical trials for obesity was abandoned after phase $\mathrm{IIb}$ [29]. Initial studies with GI181771X showed it to cause significant weight loss when participants were fed ad libitum [30]. However, participants in this longer-term study by Jordan et al [29] were placed on a hypocaloric diet, masking any potential beneficial effects compared with the placebo group, thereby leading to questioning of the validity of the trial and its conclusions [31, 32].

In the present study, sub-chronic administration of (pGluGln)-CCK-8 was not associated with any detrimental effects on behaviour or locomotor activity (data not shown). Similarly, infusion of CCK- 8 in healthy individuals and individuals with type 2 diabetes exhibited clear glucose-lowering actions without any adverse effects [33]. Thus, there still appears to be significant clinical therapeutic potential for a stable and specific CCK receptor agonist such as (pGluGln)-CCK-8, which has an extended half-life of 2234 min compared with $2-4 \mathrm{~min}$ for CCK-8 (data not shown). The difference between in vitro stability in the current study and the estimated in vivo half-life data presumably reflects tissue accumulation, liver metabolism and kidney filtration of the peptide.

In harmony with this, fasting and basal hyperglycaemia, and intraperitoneal and oral glucose tolerance were all significantly improved in (pGlu-Gln)-CCK-8-treated high-fatfed mice. Thus, despite no obvious change in insulin, circulating glucose was significantly decreased. Further, oral and i.p. nutrient challenge resulted in significantly decreased glucose levels in (pGlu-Gln)-CCK-8-treated mice compared 

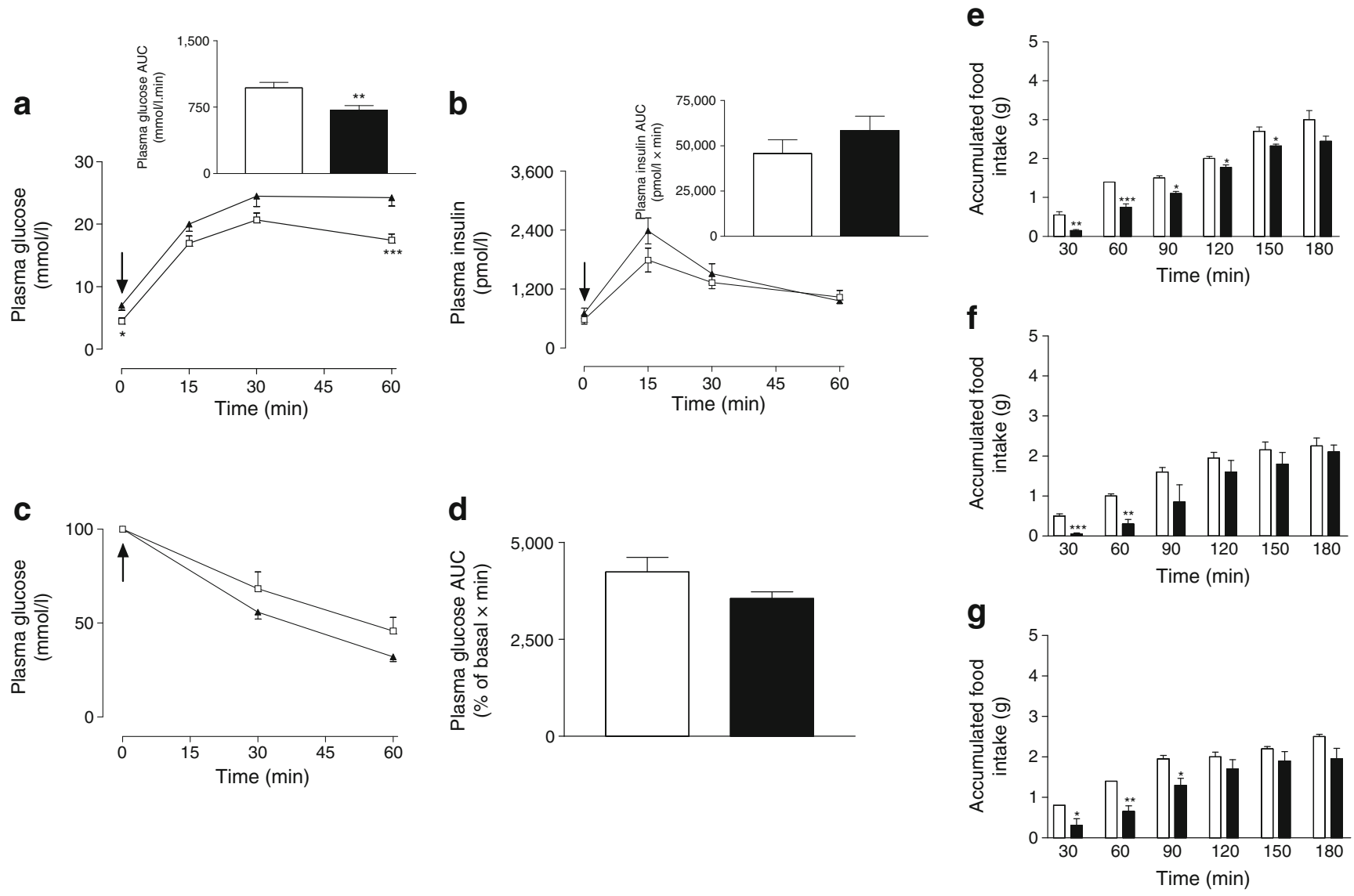

Fig. 8 Effect of twice daily (pGlu-Gln)-CCK-8 administration on glucose tolerance $(\mathbf{a}, \mathbf{b})$ and plasma insulin response to glucose $(\mathbf{c}, \mathbf{d})$ insulin sensitivity and development of tolerance (e-g) in ob/ob mice. Tests were conducted after twice-daily treatment with (pGlu-Gln)CCK-8 (25 nmol/ $/ \mathrm{kg})$ for 18 days. (a, b) Glucose $(18 \mathrm{mmol} / \mathrm{kg})$ was administered to non-fasted mice at the time indicated by the arrow. Plasma glucose and insulin AUC values for 0-60 min post injection are shown in insets. (c) Insulin $(20 \mathrm{U} / \mathrm{kg})$ was administered to non-fasted mice at the time indicated by the arrow. (d) AUC values for 0-60 min

with high-fat-fed controls, despite similar insulin concentrations. Although we cannot rule out changes in early insulin release missed by limited blood sampling, this again implies a positive effect on insulin sensitivity. This was confirmed at the end of the study by substantial insulininduced reductions in blood glucose levels in (pGlu-Gln)CCK-8-treated mice. This effect may be a consequence of reduced adipose tissue mass. Interestingly, the effects of the peptide were not associated with changes in energy expenditure and were not reproduced by simple dietary restriction, suggesting multiple actions of (pGlu-Gln)-CCK-8. However, circulating glucagon levels were unaltered, suggesting that alterations in glucagon secretion did not contribute to the observed beneficial effects of (pGlu-Gln)-CCK-8. Furthermore, the triacylglycerol content of liver as well as pancreatic tissue was decreased, suggesting improvement of peripheral insulin action and insulin secretory dynamics. In keeping with post injection are also shown. (e-g) Food intake was recorded in overnight-fasted high-fat-fed mice previously treated for 18 days twice daily with (pGlu-Gln)-CCK-8 (25 nmol/kg) on day 19 (e), 21 (f) and 25 (g) following acute administration of either saline or (pGlu-Gln)CCK-8 (25 nmol $/ \mathrm{kg})$. Squares and white bars, saline; triangles and black bars, (pGlu-Gln)-CCK-8. Values are means \pm SEM for eight mice. ${ }^{*} p<0.05, * * p<0.01$ and ${ }^{* * *} p<0.001$ compared with saline group

this, recent evidence suggests an integral role for CCK as a regulator of insulin sensitivity, especially during high-fat feeding [22]. Essentially similar observations were made in genetically obese diabetic $o b / o b$ mice treated twice daily with (pGlu-Gln)-CCK-8. It is interesting that CCK-deficient mice are also resistant to diet-induced obesity [22], highlighting the plasticity of signalling pathways involved in energy intake and weight regulation. Thus, the metabolic benefits of (pGluGln)-CCK-8 therapy at the dose employed are likely mediated by reduced body-weight gain and improved insulin sensitivity rather than prominent direct insulin secretory actions. Indeed, (pGlu-Gln)-CCK-8 had no effect on insulin action when administered in combination with insulin to treatment-naive normal mice. Moreover, comparing the acute insulinotropic actions of (pGlu-Gln)-CCK-8 in vitro and in vivo suggests that larger doses would be required to induce a significant insulin-releasing effect during sub-chronic testing. 
We also assessed whether $o b / o b$ mice develop a tolerance to (pGlu-Gln)-CCK-8. No evidence was found and $o b / o b$ mice injected twice daily for 18 days with $25 \mathrm{nmol} / \mathrm{kg}$ (pGlu-Gln)-CCK-8 still displayed significant inhibitory effects on feeding when administered (pGlu-Gln)-CCK8 following an 18-h fast. This observation contrasts with previous studies using native CCK-8 where tolerance appeared to develop quickly [34, 35], but agrees with more recent work using a longer-acting PEGylated version of CCK-9 [11]. One potential reason for the lack of tolerance to (pGlu-Gln)-CCK-8 could be the induction of taste aversion. However, CCK-8 has been reported to lack a tasteaversion effect [36] and (pGlu-Gln)-CCK-8 did not alter diet preference in normal or high-fat-fed mice. Although these preliminary studies on diet preference do not entirely rule out an effect of (pGlu-Gln)-CCK-8 on taste aversion, native CCK-8 does not appear to induce such a phenomenon [36].

Administration of extremely large doses of CCK has been shown to cause pancreatitis in rodents [13]. In the present study both groups of high-fat-fed mice exhibited mild abnormalities of pancreatic morphology including oedema and formation of small vacuoles in exocrine tissue. Treatment with $25 \mathrm{nmol} / \mathrm{kg}$ (pGlu-Gln)-CCK-8 twice daily did not appear to have a negative impact on islet structure, and circulating amylase and lipase concentrations were not significantly different between control and (pGlu-Gln)CCK-8-treated mice. This highlights an important facet of (pGlu-Gln)-CCK-8 action in terms of therapeutic potential, which appears no worse in terms of acute pancreatitis than either exenatide or liraglutide [37]. Indeed, alanine aminotransferase, aspartate aminotransferase and creatinine kinase tended to be lower, suggesting improved kidney and liver function after (pGlu-Gln)-CCK-8.

In conclusion, the present study has demonstrated for the first time that daily administration of the stable CCK-8 analogue, (pGlu-Gln)-CCK-8, causes sustained weight loss and improves both glucose tolerance and insulin resistance in mice with genetically and environmentally induced forms of obesity/diabetes. Thus, N-terminally modified analogues of CCK-8 may be useful as a new class of enzyme-resistant drugs for the alleviation of obesity and insulin resistance.

Acknowledgements These studies were supported by the SAAD Trading and Contracting Company (Al Khobar, Saudi Arabia) and the Department of Education and Learning, Northern Ireland.

Duality of interest N. Irwin, F. P. M. O'Harte and P. R. Flatt hold shares with Diabetica, which has patents for exploitation of peptide therapeutics.

Contribution statement NI conceived the study, participated in the analysis and interpretation of data, drafted the manuscript and revised it critically for intellectual content. PF, IAM and CRM participated in the analysis and interpretation of data, drafted the manuscript and revised it critically for intellectual content. FPMO and PRF conceived the study, drafted the manuscript and revised it critically for intellectual content. All authors approved the final version of the manuscript.

\section{References}

1. Ivy AC, Oldberg E (1928) A hormone mechanism for gallbladder contraction and evacuation. Am J Physiol 65:599-613

2. Verbaeys I, León-Tamariz F, Buyse J, de Cuyper M, Pottel H, van Boven $M$ et al (2007) PEGylated cholecystokinin prolongs satiation in rats: dose dependency and receptor involvement. $\mathrm{Br} \mathrm{J}$ Pharmacol 152:396-403

3. Cantor P, Rehfeld JF (1989) Cholecystokinin in pig plasma: release of components devoid of a bioactive $\mathrm{COOH}$-terminus. Am J Physiol 256:G53-G61

4. Rehfeld JF, Friis-Hansen L, Goetze JP, Hansen TV (2007) The biology of cholecystokinin and gastrin peptides. Curr Top Med Chem 7:1154-1165

5. Dufresne M, Seva C, Fourmy D (2006) Cholecystokinin and gastrin receptors. Physiol Rev 86:805-847

6. Liddle RA (1994) Cholecystokinin. In: Walsh JH, Dockray GJ (eds) Gut peptides biochemistry and physiology. Raven, New York, pp 175-216

7. Lavine JA, Raess PW, Stapleton DS, Rabaglia ME, Suhonen JI, Schueler KL et al (2010) Cholecystokinin is up-regulated in obese mouse islets and expands beta-cell mass by increasing beta-cell survival. Endocrinology 151:3577-3588

8. Flatt PR, Bailey CJ, Green BD (2009) Recent advances in antidiabetic drug therapies targeting the enteroinsular axis. Curr Drug Metab 10:125-137

9. Holst JJ, Vilsbøll T, Deacon CF (2009) The incretin system and its role in type 2 diabetes mellitus. Mol Cell Endocrinol 297:127-136

10. Rehfeld JF (2011) Incretin physiology beyond glucagon-like peptide 1 and glucose-dependent insulinotropic polypeptide: cholecystokinin and gastrin peptides. Acta Physiol (Oxf) 201:405-411

11. Verbaeys I, León-Tamariz F, Buyse J, Decuypere E, Pottel H, Cokelaere M (2009) Lack of tolerance development with longterm administration of PEGylated cholecystokinin. Peptides 30:699-704

12. Verbaeys I, León-Tamariz F, Pottel H, Decuypere E, Swennen Q, Cokelaere M (2008) PEGylated cholecystokinin is more potent in inducing anorexia than conditioned taste aversion in rats. $\mathrm{Br} \mathrm{J}$ Pharmacol 155:417-423

13. Peter SA, D'Amato M, Beglinger C (2006) CCK1 antagonists: are they ready for clinical use? Dig Dis 24:70-82

14. Hoffmann P, Eberlein GA, Reeve JR Jr, Bünte RH, Grandt D, Goebell $\mathrm{H}$ et al (1993) Comparison of clearance and metabolism of infused cholecystokinins 8 and 58 in dogs. Gastroenterology 105:1732-1736

15. Migaud M, Durieux C, Viereck J, Soroca-Lucas E, FourniéZaluski MC, Roques BP (1996) The in vivo metabolism of cholecystokinin (CCK-8) is essentially ensured by aminopeptidase A. Peptides 17:601-607

16. O'Harte FP, Mooney MH, Kelly CM, Flatt PR (1998) Glycated cholecystokinin- 8 has an enhanced satiating activity and is protected against enzymatic degradation. Diabetes 47:1619-1624

17. Kerr BD, Irwin N, O'Harte FP, Bailey CJ, Flatt PR, Gault VA (2009) Fatty acid derivatised analogs of glucose-dependent insulinotropic polypeptide with improved antihyperglycaemic and insulinotropic properties. Biochem Pharmacol 78:1008-1016

18. McClenaghan NH, Barnett CR, Ah-Sing E, Abdel-Wahab YH, O'Harte FP, Yoon TW et al (1996) Characterization of a novel glucose-responsive insulin-secreting cell line, BRIN-BD11, produced by electrofusion. Diabetes 45:1132-1140 
19. Flatt PR, Bailey CJ (1981) Abnormal plasma glucose and insulin responses in heterozygous lean $(\mathrm{ob} /+)$ mice. Diabetologia 20:573577

20. Montgomery IA, Irwin N, Flatt PR (2010) Active immunization against $\left(\mathrm{Pro}^{3}\right)$ GIP improves metabolic status in high-fat-fed mice. Diabetes Obes Metab 12:744-751

21. Bailey CJ, Flatt PR, Atkins TW (1982) Influence of genetic background and age on the expression of the obese hyperglycemic syndrome in Aston ob/ob mice. Int J Obes 6:11-21

22. Lo CM, Obici S, Dong HH, Haas M, Lou D, Kim DH et al (2011) Impaired insulin secretion and enhanced insulin sensitivity in cholecystokinin-deficient mice. Diabetes 60:2000-2007

23. Ali S, Lamont BJ, Charron MJ, Drucker DJ (2011) Dual elimination of the glucagon and GLP-1 receptors in mice reveals plasticity in the incretin axis. J Clin Invest 121:1917-1929

24. Layden BT, Durai V, Newman MV, Marinelarena AM, Ahn CW, Feng $\mathrm{G}$ et al (2010) Regulation of pancreatic islet gene expression in mouse islets by pregnancy. J Endocrinol 207:265-279

25. Mack CM, Moore CX, Jodka CM, Bhavsar S, Wilson JK, Hoyt JA et al (2006) Antiobesity action of peripheral exenatide (exendin-4) in rodents: effects on food intake, body weight, metabolic status and side-effect measures. Int J Obes (Lond) 30:1332-1340

26. Chen $H$, Kent S, Morris MJ (2006) Is the CCK2 receptor essential for normal regulation of body weight and adiposity? Eur J Neurosci 24:1427-1433

27. Bradwejn J (1993) Neurobiological investigations into the role of cholecystokinin in panic disorder. J Psychiatry Neurosci 18:178188
28. Wang H, Wong PT, Spiess J, Zhu YZ (2005) Cholecystokinin-2 (CCK2) receptor-mediated anxiety-like behaviors in rats. Neurosci Biobehav Rev 29:1361-1373

29. Jordan J, Greenway FL, Leiter LA, Li Z, Jacobson P, Murphy K et al (2008) Stimulation of cholecystokinin-A receptors with GI181771X does not cause weight loss in overweight or obese patients. Clin Pharmacol Ther 83:281-287

30. Roses AD (2004) Pharmacogenetics and drug development: the path to safer and more effective drugs. Nat Rev Genet 5:645-656

31. Roses AD (2009) Stimulation of cholecystokinin-A receptors with G1181771X a failed clinical trial that did not test the pharmacogenetic hypothesis for reduction of food intake. Clin Pharmacol Ther 85:362-365

32. Neary MT, Batterham RL (2009) Gut hormones: implications for the treatment of obesity. Pharmacol Ther 124:44-56

33. Ahrén B, Holst JJ, Efendic S (2000) Antidiabetogenic action of cholecystokinin- 8 in type 2 diabetes. J Clin Endocrinol Metab 85:1043-1048

34. Mineka S, Snowdon CT (1978) Inconsistency and possible habituation of CCK-induced satiety. Physiol Behav 21:65-72

35. Crawley JN, Beinfeld MC (1983) Rapid development of tolerance to the behavioural actions of cholecystokinin. Nature 302:703-706

36. West DB, Greenwood MR, Marshall KA, Woods SC (1987) Lithium chloride, cholecystokinin and meal patterns: evidence that cholecystokinin suppresses meal size in rats without causing malaise. Appetite 8:221-227

37. Ahrén B (2011) The future of incretin-based therapy: novel avenues-novel targets. Diabetes Obes Metab 13(Suppl 1):158-166 